\title{
EDITORIAL
}

\section{Does nonchemical inhibition of respiratory output occur during mechanical ventilation?}

\author{
F. Lofaso
}

Breathing is a complex motor activity originating in a central neural drive from the medulla and pons. This central neural drive is controlled via homeostatic reflexes involving specialized organs, called chemoreceptors, which sense body fluid composition changes reflecting $\mathrm{O}_{2}$ demand and $\mathrm{CO}_{2}$ production. Some chemoreceptors are located in the peripheral arteries and others in the central nervous system. However, the reflexes initiated by chemoreceptors, which underlie the chemical control of breathing, are not the only mechanisms involved in the control of breathing. Important contributions are also made by other regions of the brain and by peripheral afferent information from receptors in the airways and respiratory muscles. The resulting pattern of control is efficient and responsive to change.

It is generally admitted that ventilatory loading of the respiratory system can stimulate the respiratory controller independently from chemical feedback [1]. The mechanism of respiratory controller inhibition during unloading by mechanical ventilation is less clear, although mechanical ventilation has been used for many years to treat patients with respiratory failure.

The respiratory control system has several options for utilizing the unloading induced by mechanical ventilation. Central respiratory output can remain chiefly dependent on chemical feedback, diminishing only when the ventilatory assistance produces more ventilation. Alternatively, respiratory output can be reduced by mechanical ventilation in the absence of changes in minute ventilation and haematosis. Any intermediate situation between these two extremes is also possible, and the response may vary with the experimental or clinical conditions, including $\mathrm{CO}_{2}$ level, and with the mode of mechanical ventilation.

The approach by XIROUCHAKI et al. [2] described in this issue of the European Respiratory Journal is an original method for studying the determinants of respiratory control during mechanical ventilation by pressure support (PS) in conscious patients. By modifying the PS level by $5 \mathrm{cmH}_{2} \mathrm{O}$, XirouchaKi et al. [2] were able to suddenly decrease or increase the unloading and to look for an attendant sudden change in respiratory output. An interesting feature of transient PS unloading is that chemical feedback remains unchanged initially, whereas nonchemical influences, e.g. via sensory pathways, are immediately modified. XIROUCHAKI et al. [2] found that transient changes in PS-induced unloading did not modify the

Correspondence: F. Lofaso, Physiologie-Explorations Fonctionnelles, Hôpital Raymond Poincaré, 104 boulevard Raymond Poincaré, 92380 Garches, France. Fax: 33147107943 respiratory output of the following two breaths. Similarly, in studies of patients receiving synchronized intermittent mandatory ventilation (SIMV), IMSAND et al. [3] and MARINI et al. [4] found that inspiratory effort did not differ between spontaneous and mandatory breaths.

What is the physiological relevance of these clinical results? XIROUCHAKI et al. [2] interpreted their results as evidence that respiratory activity in humans is not sensitive to nonchemical influences. Conversely, IMSAND et al. [3] suggested that respiratory output is preprogrammed and cannot be altered either during the breath itself or during the preceding breath by transient changes in the activity of peripheral afferents due to an abrupt change in load. This hypothesis is consistent with the concept that respiration is partially self-modulating, or self-amplifying, probably through the mechanism of reverberating central neuronal circuits. However, preprogramming may also be directly influenced by several afferent neural signals related to blood gases and respiratory mechanics. TAWADrous and EldRIDGE [5] have also suggested the existence of preprogramming in humans. They found evidence of respiratory centre inertia, or memory, unrelated to the inertia of the chemical feedback. Thus, the immediate respiratory output response to any stimulus may be governed to a significant extent by this central effect, rather than only by the characteristics of the stimulus and its receptors. If this is the case, the experimental condition proposed in the study by XIROUCHAKI et al. [2] may be less than ideal for confirming or ruling out the existence of nonchemical feedback.

The existence of nonchemical inhibition of respiratory output was first suggested during controlled mechanical ventilation (CMV) in normal subjects. Altose et al. [6], SIMON and coworkers [7, 8], and others [9-11] found that after suppression of respiratory output by mechanical hyperventilation the level of end-tidal partial pressure of carbon dioxide $\mathrm{PCO}_{2}$ end-tidal pressure of carbon dioxide $P$ ET, $\left.\mathrm{CO}_{2}\right)$ at which respiratory output was detectable was several $\mathrm{mmHg}$ above the eupneic $P$ ET, $\mathrm{CO}_{2}$. HenKe et al. [12] reported that returning $P \mathrm{ET}, \mathrm{CO}_{2}$ to the spontaneous level by adding $\mathrm{CO}_{2}$ to the inspired air during mechanical hyperventilation did not completely restore respiratory activity to the level observed during spontaneous breathing. Some of these studies were performed during sleep $[8,10,12]$, indicating that these nonchemical inhibitory effects are largely of peripheral origin and independent from higher brain centres.

Over the last few years, partial ventilatory-support techniques such as PS and proportional assist ventilation (PAV) have generated considerable interest as alternatives 
to controlled ventilation. Partial ventilatory support techniques decrease respiratory output, although it is the patient's inspiratory effort that triggers the ventilatorassisted breath.

Nonchemical feedback has been documented during PS. In agreement with the data obtained by HeNKE et al. [12] during mechanical ventilation by CMV, studies in control subjects conducted by SCHEID et al. [13] and FAUROUX et al. [14] showed that returning $P \mathrm{ET}, \mathrm{CO}_{2}$ to the spontaneous level by adding $\mathrm{CO}_{2}$ to the inspired air during mechanical hyperventilation by PS did not completely restore respiratory activity to the level observed during spontaneous breathing.

Nonchemical inhibition of respiratory output during PS has also been suggested in patients with respiratory failure $[15,16]$. In a study of intensive care unit patients, BonMARCHAND et al. [16] found that an initial flow rate increase during PS was associated with a decrease in diaphragmatic activity, although $P \mathrm{ET}, \mathrm{CO}_{2}$ and minute ventilation remained unchanged over a broad range of flow rate variation. Similarly, in a recent study comparing several PS devices in critically-ill patients undergoing weaning from mechanical ventilation, we detected no differences in arterial $\mathrm{PCO}_{2}$ or minute ventilation, but found that the PS device associated with the highest initial flow rate was more efficient in reducing respiratory output than the PS device associated with the lowest initial flow rate [15]. These findings suggest that intubated patients with respiratory failure may use the additional unloading associated with the initial flow rate increase to reduce respiratory muscle work rather than to produce more ventilation.

PAV is different from the other modes of assisted ventilation. After the initial active triggering phase during PS, inspiration can be virtually passive and tidal volume $(V \mathrm{~T})$ can be above physiological values despite minimal respiratory output [17]. During PAV, in contrast, the assistance is proportional to the respiratory muscle activity, and $V \mathrm{~T}$ depends on the duration and strength of respiratory muscle activity. These differences in experimental techniques and ventilatory modes may account for the apparent discrepancy between findings from studies of PS and a report by GEORGOPOULOS et al. [18] stating that during PAV the decrease in respiratory motor output was only due to the change in $P \mathrm{ET}, \mathrm{CO}_{2}$. Interestingly, in a very recent study [19], the same group found that when chemical influences were controlled in normal subjects the inspiratory effort was influenced by the mode of mechanical ventilation, being lower with PAV than with other modes of mechanical ventilation. The results of these two studies remain controversial.

Finally, the apparent discrepancies across studies may be ascribable to differences in the initial flow rate induced by the ventilator. When this initial flow rate is lower than the flow demand, chemical feedback probably dominates the response of the respiratory controller. In contrast, when it is greater than the flow demand, nonchemical inhibition of respiratory activity may occur.

Among studies performed to investigate the mechanism of nonchemical inhibition of mechanical ventilation in humans, some compared the response to mechanical ventilation between control subjects and patients with loss of a sensory pathway $[7,11,20,21]$. The nonchemical inhibition associated with mechanical ventilation persisted in $\mathrm{C} 4$ to $\mathrm{C} 5$ quadriplegics with intercostal deafferentation [20]. Studies in lung transplant patients with bilateral vagal denervation yielded conflicting results: persistence of nonchemical inhibition during mechanical ventilation was observed by SimON et al. [7] and by LEEVERS et al. [21] but not by others [11]. Thus, the pathways of nonchemical inhibition associated with mechanical ventilation remain unclear.

In conclusion, most published data support the existence of nonchemical inhibition of respiratory output during mechanical ventilation. This nonchemical inhibition may explain why mechanical ventilation is effective in patients with imminent failure of respiratory muscles in the absence of concomitant improvement in arterial blood gas values. There is clearly a need for improving the understanding of the factors that determine the occurrence and magnitude of nonchemical feedback. Further studies are needed to understand the mechanisms of this nonchernical influence.

\section{References}

1. Cherniak N, Altose M. Respiratory response to ventilatory loading. In: Hornbein $\mathrm{T}$, ed. Regulation of breathing. New York, Marcel Dekker, 1981; pp. 905-964.

2. Xirouchaki N, Kondili E, Mitrouska I, Siafakas N, Georgopoulos D. Early and late response of respiratory motor output to varying pressure support levels in mechanically ventilated patients with acute lung injury. Eur Respir J 1999; 14: 508-516.

3. Imsand C, Feihl F, Perret C, Fitting J. Regulation of inspiratory neuromuscular output during synchronized intermittent mechanical ventilation. Anesthesiology 1994; 80: $13-22$.

4. Marini J, Smith T, Lamb V. External work output generation during synchronized intermittent mechanical ventilation. Am Rev Respir Dis 1988; 138: 1169-1179.

5. Tawadrous FD, Eldridge FL. Posthyperventilation breathing patterns after active hyperventilation in man. J Appl Physiol 1974; 37: 353-356.

6. Altose M, Castele R, Connors A, Dimarco A. Effects of volume and frequency of mechanical ventilation on respiratory activity in humans. Respir Physiol 1986; 66: 171-180.

7. Simon PM, Skatrud JB, Badr MS, Griffin DM, Iber C, Dempsey JA. Role of airway mechanoreceptors in the inhibition of inspiration during mechanical ventilation in humans. Am Rev Respir Dis 1991; 144: 1033-1041.

8. Simon P, Dempsey J, Landry D, Skatrud J. Effect of sleep on respiratory muscle activity during mechanical ventilation. Am Rev Respir Dis 1993; 147: 32-37.

9. Prechter GC, Nelson SB, Hubmayr RD. The ventilatory recruitment threshold for carbon dioxide. Am Rev Respir Dis 1990; 141: 758-764.

10. Ingrassia TS, Nelson SB, Harris CD, Hubmayr RD. Influence of sleep state on $\mathrm{CO}_{2}$ responsiveness. $\mathrm{Am} \mathrm{Rev}$ Respir Dis 1991; 144: 1125-1129.

11. Lofaso F, Simmoneau G, Le Roy Ladurie F, et al. Frequency of mechanical ventilation and respiratory activity after double lung transplantation. Respir Physiol 1993; 92: 319-327.

12. Henke K, Arias A, Skatrud J, Dempsey J. Inhibition of inspiratory muscle activity during sleep. Am Rev Respir Dis 1988; 138: 8-15.

13. Scheid P, Lofaso F, Isabey D, Harf A. Respiratory response to inhaled $\mathrm{CO}_{2}$ during positive inspiratory pressure in humans. J Appl Physiol 1994; 77: 876-882. 
14. Fauroux B, Isabey D, Desmarais G, Brochard L, Harf A, Lofaso F. Non-chemical influence of inspiratory pressure support on inspiratory activity in humans. J Appl Physiol 1998; 85: 2169-2175.

15. Lofaso F, Brochard L, Hang T, Lorino H, Harf A, Isabey D. Home versus intensive-care pressure support devices, experimental and clinical comparison. Am J Respir Crit Care Med 1996; 153: 1591-1599.

16. Bonmarchand G, Chevron V, Chopin C, et al. Increased initial flow rate reduces inspiratory work of breathing during pressure support ventilation in patients with exacerbation of chronic obstructive pulmonary disease. Intensive Care Med 1996; 22: 1147-1154.

17. Azarian R, Lofaso F, Zerah F, et al. Assessment of respiratory compliance in awake subjects using pressure support. Eur Respir 1993; 6: 552-558.
18. Georgopoulos D, Mitrouska I, Webster V, Bshouty Z, Younes M. Effect of inspiratory muscle unloading on the response of respiratory motor output to $\mathrm{CO}_{2}$. Am J Respir Crit Care Med 1997; 155: 2000-2009.

19. Mitrouska I, Xirouchaki N, Patakas D, Siafakas N, Georgopoulos D. Effectiveness of chemical feedback during assisted mechanical ventilation in conscious normal humans. Eur Respir J 1999; 13: 873-882.

20. Simon P, Griffin D, Landry D, Skatrud J. Inhibition of respiratory activity during passive ventilation: a role for intercostal afferents? Respir Physiol. 1993; 92: 5364.

21. Leevers AM, Simon PM, Xi L, Dempsey JA. Apnoea following normocapnic mechanical ventilation in awake mammals: a demonstration of control system inertia. $J$ Physiol 1993; 472: 749-768. 